\title{
Conservative versus invasive treatment in hypertrophic obstructive cardiomyopathy: an echocardiography study
}

\author{
Honek $\mathrm{T}^{1,2}$, Krejci $\mathbf{J}^{1,2}$, Machal $\mathbf{J}^{3,4}$, Groch $\mathrm{L}^{1,4}$, Sitar $\mathbf{J}^{1,4}$, Meluzin $\mathbf{J}^{1,2,4}$, Spinarova $\mathrm{L}^{1,2}$ \\ Department of Cardiovascular Diseases, St. Anne's University Hospital Brno, Brno, Czech Republic. \\ jan.krejci@fnusa.cz
}

\begin{abstract}
AIM AND METHODS: The aim of our study was to compare the development of echocardiographic parameters and functional status of patients with hypertrophic obstructive cardiomyopathy (HOCM) treated conservatively $(n=41)$ or by alcohol septal ablation (ASA; $n=39)$.

RESULTS: Left ventricular outflow tract gradient (LVOTG) decreased in the first year by $53.7 \pm 36.4 \mathrm{mmHg}$ in ASA group versus $5.5 \pm 47.1 \mathrm{mmHg}$ in conservatively treated group $(p<0.001)$, in the third year by $53.1 \pm 41.4$ $\mathrm{mmHg}$ versus $23.9 \pm 42.7 \mathrm{mmHg}(\mathrm{p}=\mathrm{NS})$ and in the fifth year, the reduction of LVOTG was $52.1 \pm 44.5 \mathrm{mmHg}$ in ASA group and $3.0 \pm 63.2 \mathrm{mmHg}$ in conservatively treated group $(p<0.05)$. Change in NYHA class in the first year was $-1.1 \pm 0.4$ versus $0.1 \pm 0.5$, in the third year $-1.0 \pm 0.6$ versus $0.1 \pm 0.4$ and in the fifth year $-0.8 \pm 0.5$ versus $0.1 \pm 0.4$ (all $p<0.001$ ).

CONCLUSION: Our results showed for the first time that decline of LVOTG after ASA creates a favorable left ventricle remodeling and leads to significant improvement of functional status of HOCM patients in comparison with conservative treatment (Tab. 3, Fig. 2, Ref. 42). Text in PDF www.elis.sk.

KEY WORDS: hypertrophic obstructive cardiomyopathy, alcohol septal ablation, conservative treatment, invasive treatment, echocardiography.
\end{abstract}

\begin{abstract}
Abbreviations: $\mathrm{H}(\mathrm{O}) \mathrm{CM}$ - Hypertrophic (obstructive) cardiomyopathy; ASA - Alcohol septal ablation; LVOT(G) - Left ventricular outflow tract (gradient); NYHA - New York Heart Association; IVS - Interventricular septum; LGE - Late gadolinium enhancement; LVEF - Left ventricular ejection fraction; SAM - Systolic anterior motion; NYHA - New York Heart Association; LV - Left ventricle; PM DDD - Dual-chamber pacemaker; ICD - Implantable cardioverter defibrillator; MRI - Magnetic resonance imaging; PW - Posterior wall; LVEDD - Left ventricular end-diastolic diameter; LVESD - Left ventricular end-systolic diameter; RV - Right ventricle; LA - Left atrium; Mi reg - Mitral regurgitation; TCP - Temporary cardiac pacing; LCA - Left coronary artery; ACCF/ AHA - American College of Cardiology Foundation/American Heart Association; ESC - European Society of Cardiology
\end{abstract}

\footnotetext{
${ }^{1}$ Department of Cardiovascular Diseases, St. Anne's University Hospital Brno, Brno, Czech Republic, ${ }^{2}$ Faculty of Medicine, Masaryk University Brno, Brno, Czech Republic, ${ }^{3}$ Department of Pathophysiology, Masaryk University Brno, Brno, Czech Republic, and ${ }^{4}$ International Clinical Research Center, St. Anne's University Hospital Brno, Brno, Czech Republic

Address for correspondence: J. Krejci, MD, PhD, Department of Cardiovascular Diseases, St. Anne's University Hospital, Pekarska 53, CZ-656 91 Brno, Czech Republic.

Phone: +420.54318 2405, Fax: +420.54318 2205

Acknowledgement: The study was supported by the Specific University Research Grant MUNI/A/1270/2015 and by the project no. LQ1605 from the National Program of Sustainability II.
}

\section{Introduction}

Hypertrophic cardiomyopathy (HCM) is a disorder defined by thickening of left ventricle (LV) walls or increased mass of myocardium of non-dilated LV without explanatory hemodynamic reasons, such as hypertension or valvular disease, able to cause a certain degree of hypertrophy $(1,2,3,4)$. HCM is the most common genetic heart disorder with an autosomal dominant type of inheritance caused by a mutation in genes encoding most commonly cardiac sarcomeric proteins with a prevalence of $1: 500$ (1, $3,4)$. Hypertrophy of the interventricular septum (IVS), elongated leaflets of the mitral valve and papillary muscles abnormalities are the most common reasons for the presence of obstruction in the left ventricular outflow tract (LVOT) (5). Intraventricular obstruction is present in approximately two thirds of patients - one half of them has obstruction at rest (resting obstruction) and the second half after stress (latent obstruction). The remaining one third of individuals has neither obstruction at rest nor during exercise (nonobstructive type of HCM) $(3,6)$. LVOT obstruction is most often associated with the presence of systolic anterior motion (SAM) of the anterior mitral leaflet. Clinical diagnosis of HCM is based on the detection of the typical phenotype of this disease usually by echocardiography, as the basic diagnostic method, with the presence of LV wall hypertrophy (particularly IVS) and non-dilated LV cavity. Magnetic resonance imaging (MRI) is another, modern and more accurate method, which is essential especially in subjects poorly evaluable by echocardiography. This method allows, 
besides assessment of LV kinetics and the extent of hypertrophy, to show the presence and the extent of myocardial fibrosis by late gadolinium enhancement (LGE). The extent of LGE is useful in prediction of cardiovascular mortality and the mere presence of LGE seems to be associated with a higher incidence of ventricular arrhythmias and sudden cardiac death $(1,3,7)$. Intraventricular obstruction is the main cause of clinical symptomatology of these patients. Typical symptoms are shortness of breath, angina pectoris, palpitations, stress-induced syncope or sudden cardiac death (8). The treatment is complex and is selected according to symptomatology and the presence or absence of gradient in LVOT (LVOTG). The first step in symptomatic patients is pharmacological therapy. Non-pharmacological approach can be used in selected cases with persistent symptoms and significant LVOT obstruction. The basic pharmacotherapy consists of drugs that reduce oxygen consumption and prolong diastolic filling of LV (5). The first option of drug therapy for patients with hypertrophic obstructive cardiomyopathy (HOCM) are beta-blockers, which reduce primarily stress-induced LVOTG and lead to relief of symptoms (9). Second line of treatment is verapamil, non-dihydropyridine calcium antagonist, which, in contrast to beta-blockers, reduces mainly resting LVOTG and this treatment also leads to the improvement of clinical status (4). Verapamil also has a vasodilatory effect, which may cause an increase of LVOT gradient, therefore it is required to be used with care in individuals with high LVOTG (10). Another treatment option is disopyramid, which is quite often used in North America (11). In Europe, it is administered much less frequently and in our group was not used in any patient. In obstructive types of HCM with persisting symptoms despite the maximal tolerated pharmacotherapy, one of the three interventional methods can be used to reduce LVOTG. The oldest of them is surgical myectomy, which was introduced into practice in the 1960's and is still considered (especially in the United States) as the first option. Ten years later, dual-chamber pacemaker (PM DDD) implantation with apical pre-excitation was introduced and after initial promising results this method was relegated to the background later $(12,13$, 14). If suitable coronary anatomy is present, the third method, alcohol septal ablation (ASA), can be indicated. This is a preferred option in most European countries including the Czech Republic. It is the most recent method of non-pharmacological treatment, which was performed for the first time by Ulrich Sigwart in 1994 in London (15). This is an interventional cardiological method based on injection of absolute alcohol most often into the first septal branch supplying the basal portion of IVS, causing infarction in that region. It results later in scaring and thinning of hypertrophic IVS leading to enlargement of LVOT, reduction of LVOTG and improvement of symptoms. Furthermore, LV remodeling with regression of its hypertrophy is present, even beyond the intervened segments of $\operatorname{LV}(4,7)$.

\section{Aim}

The aim of our retrospective study was to compare development of echocardiographic parameters and functional status in short-term, mid-term and long-term follow-up in HOCM patients who were treated conservatively, i.e. by pharmacological treatment or had no therapy, and interventional, i.e. by ASA, and to compare the change of echocardiographic parameters and functional status between both groups in the above stated follow-up periods.

\section{Methods}

Group of patients and evaluated parameters

For evaluation, we used data from a monocentric registry of HCM patients collected during the years 2000-2015 dispensarized at Department of Cardiovascular Diseases, St. Anne's University Hospital Brno, Czech Republic.

Inclusion criteria were as follows: 1) echocardiographic picture of $\mathrm{HCM}$ with LV ejection fraction (LVEF) $\geq 50 \%, 2$ ) resting or stress-induced LVOTG $\geq 30 \mathrm{mmHg}, 3$ ) IVS $\geq 15 \mathrm{~mm}, 4$ ) follow-up duration $\geq 1$ year. Exclusion criteria were the following: 1) severe arterial hypertension, 2) hemodynamically significant aortic stenosis, 3) proven storage and infiltrative myocardial disorder, 4) history of PM/ICD DDD implantation, 5) history of surgical myectomy.

The trial included 80 patients (54 men and 26 women) with the average age of $57.5 \pm 12.8$ years, who were divided into two groups according to treatment regimen. The first group treated conservatively included 41 patients (30 men and 11 women), 39 patients were enrolled into the second group treated by ASA ( 24 men and 15 women). The following parameters were evaluated: maximal resting gradient in LVOT (LVOTG), thickness of interventricular septum (IVS), thickness of LV posterior wall (PW), LV end-diastolic diameter (LVEDD), LV end-systolic diameter (LVESD), right ventricle diameter (RV), left atrium diameter (LA), LV ejection fraction (LVEF), mitral regurgitation degree (Mi reg), systolic anterior motion (SAM) and NYHA classification. The follow-up periods were 1 year (short-term), 3 years (mid-term) and 5 years (long-term). First, the development of the parameters was evaluated in both groups in the above defined time periods and subsequently changes of the parameters between both groups were compared (the minus sign indicates decrease or reduction in the parameter value).

\section{Statistical analysis}

Normality of the data were tested by Kolmogorov-Smirnov test and by visual inspection of the histograms and normal probability plots. Changes of RV, IVS, LVEDD, LVESD, PW, LA, LVEF and LVOTG were assessed by repeated measures ANOVA and Dunnett post hoc test separately for both, conservative group and ASA group. Prior to that, LVOTG was log-transformed to fit normal distribution and only the values of resting LVOTG were used for statistical evaluation due to the lack of stress-induced LVOTG measurements in patients where significant resting obstruction had already been present. In the case of ordinal parameters - mitral regurgitation and NYHA classification - Friedman test with Hochberg post hoc test was used. SAM was assessed using Cochran Q test and a series of McNemar tests with Bonferroni correction were further employed. The heart failure degree was also categorized as mild $(\mathrm{NYHA} \leq \mathrm{II})$ or severe $(\mathrm{NYHA}>\mathrm{II})$ and 

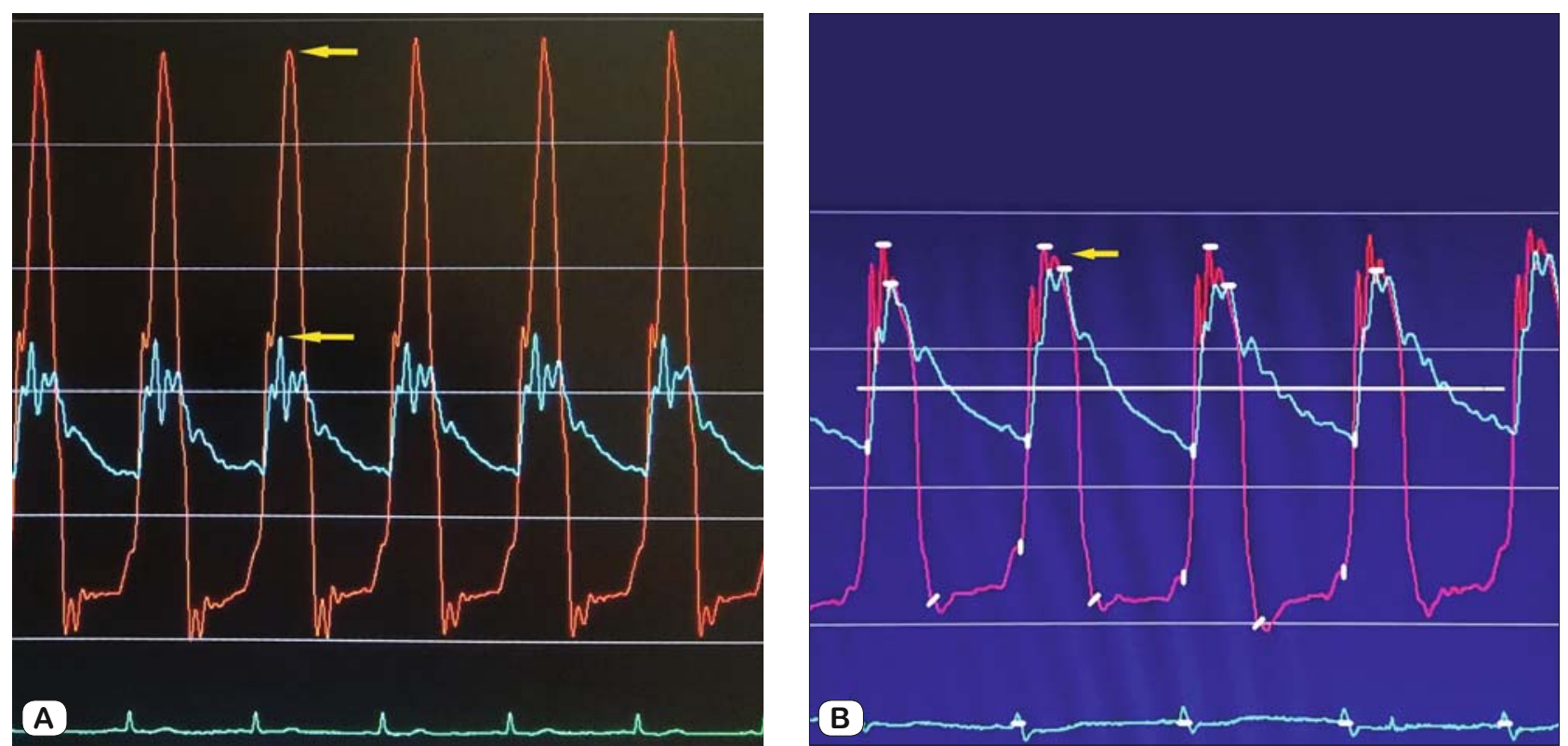

Fig. 1. Invasively measured left ventricular outflow tract (LVOT) gradient A) before alcohol septal ablation [difference between pressure curves in apical part of left ventricle (upper arrow) and in LVOT (lower arrow)] and B) after alcohol septal ablation [disappearance of difference in systolic pressures between LVOT and apex (arrow)].

was analyzed in the same way. Post hoc analyses were performed only if the null hypothesis was rejected in the general test. In all post hoc analyses, the data obtained during the follow-up were compared to baseline values that were taken as reference $(k-1$ comparison). Because the parameters were closely correlated, no further multiple testing corrections was employed.

Further, the magnitude of the changes was compared between the conservative group and the ablation group. In the case of RV, IVS, LVEDD, LVESD, PW and LA, t-tests for independent data were used. In the case of the LVEF and the LVOTG, Mann-Whitney U-test was used due to their non-normal and non-transformable distribution. Mann-Whitney U-test was also employed in Mi reg and NYHA change. In SAM, where potential change could only have three values ( $-1,0$ and 1$)$, Cochran-Armitage test for trend was used.

Because of a high drop-out rate, the baseline characteristics of the patients that were followed for the whole period of five years were compared to those that were lost before the end of the study to exclude the possibility of survival bias. T-tests for independent data, Mann-Whitney U-test and Fisher exact test were employed in this analysis.

All analyses were performed using STATISTICA software (Stat Soft, version 12), except for Cochran-Armitage test where TREND program (developed by Jürg Ott, available at url: http:// www.jurgott.org/linkage/util.htm) was used, and Hochberg post hoc comparison for Friedman test that was performed using CONTROLTEST program (Alcala-Fdez et al, 2009, available at url: http://sci2s.ugr.es/sicidm) (16).

\section{Alcohol septal ablation}

Temporary cardiac pacing (TCP) was introduced before the intervention as a prevention of periprocedural bradycardic arrhyth- mias. At first, selective coronary angiography was performed to assess the suitability of coronary arteries anatomy. Subsequently, pressure gradient was measured between catheter placed in LV apex and in LVOT (subvalvular area) at rest and after stress provoked by ventricular extrasystole or by Valsalva maneuver, less frequently by application of nitrates (Fig. 1a). Then, special overthe-wire balloon catheter was introduced into the septal branch supplying the presumed area, which participates in intraventricular obstruction (predominantly basal IVS), and encloses lumen of this vessel. Echo contrast substance was injected through the catheter and the extent and localization of the perfusion area of this septal branch was evaluated echocardiographically (17). After identifying a suitable septal branch, $96 \%$ alcohol was applied into it. The amount of injected alcohol was based on lumen size and the supplied region of appropriate septal branch (approximately 1.0 $\mathrm{ml}$ per $10 \mathrm{~mm}$ of IVS thickness). After ten minutes, the balloon was deflated, residual pressure gradient between the LV apex and LVOT was measured at rest and after above described provoking maneuvers (Fig. 1b). Finally, selective coronary angiography of left coronary artery (LCA) was performed to confirm ablation of septal branch and exclusion of incidental alcohol leak into the other part of LCA with formation of no-reflow phenomenon (5, 8 ). Electrode of TCP was left at least 24 hours, or longer if necessary, and the patient stayed in hospital with monitoring of heart rhythm for at least 5 days (18).

\section{Echocardiography}

Echocardiographic examinations were performed on GE Vivid 7, GE Vivid E9, Philips IE 33 machines and evaluated parameters were measured according to the ACCF/AHA and the ESC guidelines for diagnosis and treatment of $\operatorname{HCM}(1,3)$. Stress-induced 

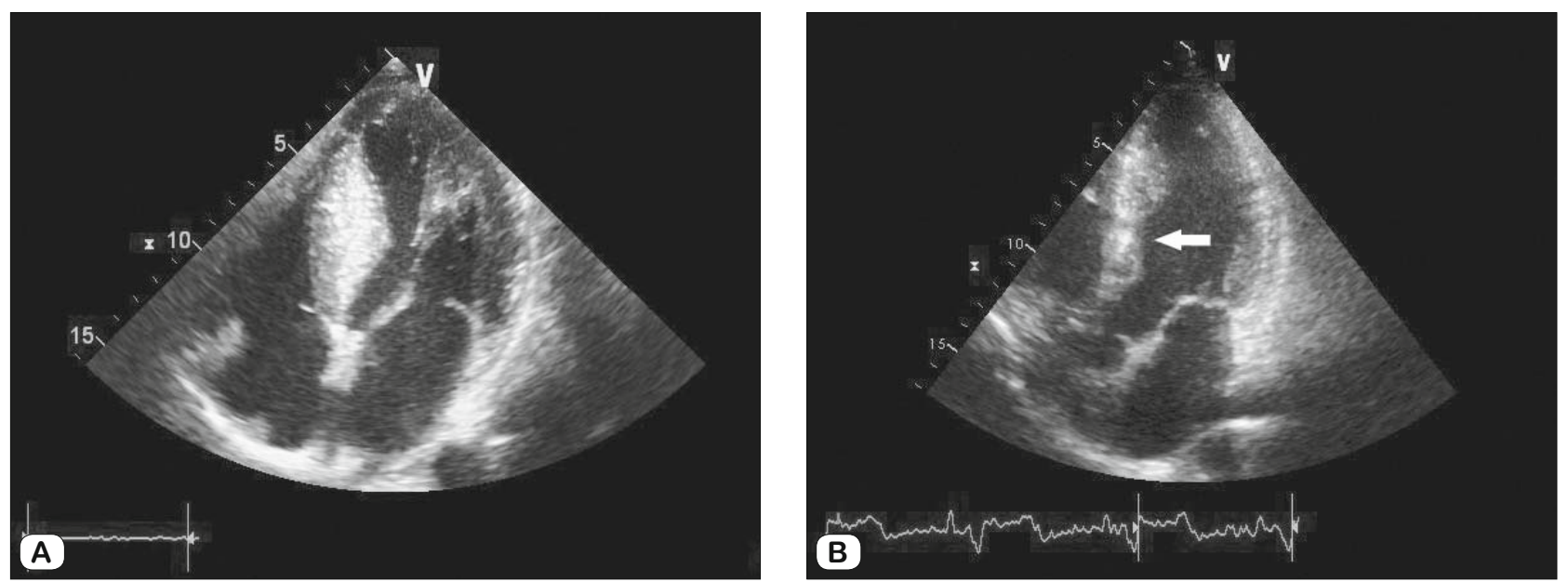

Fig. 2. Interventricular septum A) before alcohol septal ablation and B) after alcohol septal ablation (arrow shows scar with thinning of hypertrophic septum).

LVOTG was provoked mostly by using sublingual nitrates, less frequently by Valsalva maneuver (19).

\section{Results}

Patients in the ASA group were slightly older $(60.1 \pm 12.2$ versus $55.0 \pm 12.9$ years), although it was not statistically significant $(\mathrm{p}=0.07)$, they had a higher degree of mitral regurgitation $(1.4$ \pm 0.7 versus $0.8 \pm 0.7, p<0.001)$ and were also more symptomatic according to the NYHA classification $(2.9 \pm 0.2$ versus $1.8 \pm$ $0.6, p<0.001)$. Out of the total number of 80 patients, in 71 one year follow-up data were available, in 51 three years data and in 33 five years follow-up results. There was no statistically signifi-

Tab. 1. Baseline characteristics.

\begin{tabular}{|c|c|c|c|}
\hline & $\begin{array}{c}\text { Cons. group } \\
(\mathrm{n}=41)\end{array}$ & $\begin{array}{c}\text { ASA group } \\
(\mathrm{n}=39)\end{array}$ & $\mathrm{p}$ \\
\hline Age, $y$ & $55.0 \pm 12.9$ & $60.1 \pm 12.2$ & NS \\
\hline Men, n (\%) & $30(73)$ & $24(62)$ & NS \\
\hline NYHA class (mean) $\pm \mathrm{SD}$ & $1.8 \pm 0.6$ & $2.9 \pm 0.2$ & $<0.001$ \\
\hline NYHA class $>I I, n(\%)$ & $11(27)$ & $39(100)$ & $<0.001$ \\
\hline Resting LVOTG (mean) $\pm \mathrm{SD}, \mathrm{mmHg}$ & $61.7 \pm 51.0$ & $79.7 \pm 50.0$ & NS \\
\hline Resting LVOTG - median, (IR), $\mathrm{mmHg}$ & $50(24-86)$ & $83(45-100)$ & NS \\
\hline Interventricular septum (mean) $\pm \mathrm{SD}, \mathrm{mm}$ & $19.9 \pm 3.8$ & $20.8 \pm 3.1$ & NS \\
\hline Posterior wall (mean) $\pm \mathrm{SD}, \mathrm{mm}$ & $14.5 \pm 2.3$ & $15.6 \pm 3.5$ & NS \\
\hline $\mathrm{LV}$ end-diastolic diameter(mean) $\pm \mathrm{SD}, \mathrm{mm}$ & $41.7 \pm 6.0$ & $40.5 \pm 4.6$ & NS \\
\hline $\mathrm{LV}$ end-systolic diameter (mean) $\pm \mathrm{SD}, \mathrm{mm}$ & $24.7 \pm 6.1$ & $24.0 \pm 5.0$ & NS \\
\hline Right ventricle (mean) $\pm \mathrm{SD}, \mathrm{mm}$ & $28.2 \pm 3.6$ & $28.2 \pm 3.9$ & NS \\
\hline Left atrium (mean) $\pm \mathrm{SD}, \mathrm{mm}$ & $42.8 \pm 5.6$ & $44.6 \pm 7.3$ & NS \\
\hline $\mathrm{LV}$ ejection fraction (mean) $\pm \mathrm{SD}, \%$ & $68.1 \pm 7.2$ & $65.7 \pm 6.5$ & NS \\
\hline Mitral regurgitation (mean) $\pm \mathrm{SD}$ & $0.8 \pm 0.7$ & $1.4 \pm 0.7$ & $<0.001$ \\
\hline Systolic anterior motion, $\mathrm{n}(\%)$ & $37(90)$ & $37(95)$ & NS \\
\hline Amount of $96 \%$ alcohol (mean) $\pm \mathrm{SD}, \mathrm{ml}$ & & $2.2 \pm 0.7$ & \\
\hline 1-year follow-up, n (\%) & $35(85)$ & $36(92)$ & NS \\
\hline 3-year follow-up, n (\%) & $25(61)$ & $26(67)$ & NS \\
\hline 5-year follow-up, n (\%) & $15(37)$ & $18(46)$ & NS \\
\hline
\end{tabular}

Cons. - Conservative, ASA - alcohol septal ablation, SD - standard deviation, NS - non-significant, LVOTG - left ventricular outflow tract gradient, LV - left ventricle, IR - interquartile range cant difference in any baseline parameters between the patients, who remained in the study and those, who dropped out from the study. There was also no difference in the drop-out between the conservatively and the interventional treated patients. All baseline characteristics are in Table 1.

In the ASA treated group, LVOTG decreased from $79.7 \pm 50.0$ $\mathrm{mmHg}$ to $25.5 \pm 18.8 \mathrm{mmHg}$ (first year) and remained stable with $23.3 \pm 23.2 \mathrm{mmHg}$ (third year) and $26.5 \pm 29.3 \mathrm{mmHg}$ (fifth year) compared to the baseline, all $\mathrm{p}<0.001$. NYHA class declined from $2.9 \pm 0.2$ to $1.8 \pm 0.5$ (first year) and remained almost stable with $1.9 \pm 0.6$ (third year) and $2.1 \pm 0.5$ (fifth year) compared to the baseline, all $\mathrm{p}<0.001$. In the conservatively treated group, LVOTG nonsignificant decreased from $61.7 \pm 51.0 \mathrm{mmHg}$ to $55.2 \pm 51.5 \mathrm{mmHg}$ (first year), to $40.8 \pm 35.8 \mathrm{mmHg}$ (third year) and to $51.0 \pm 67.5 \mathrm{mmHg}$ (fifth year) compared to the baseline, all $\mathrm{p}=$ NS. NYHA class remained stationary for all periods $1.8 \pm$ 0.6 (baseline), $1.8 \pm 0.6$ (first year), $1.9 \pm 0.7$ (third year) and 2.0 \pm 0.6 (fifth year), all $\mathrm{p}=\mathrm{NS}$. IVS and PW thickness decreased statistically significantly during the follow-up in the ASA group, whereas in the conservative group, these two parameters tended to thickening, IVS even statistically significant. The development of all parameters in both groups is shown in Table 2 .

Comparing the changes in various parameters, both groups showed clear differences in the effect of both treatment approaches: LVOTG change in the first year was $-53.7 \pm 36.4 \mathrm{mmHg}$ in the ASA group versus $-5.5 \pm 47.1 \mathrm{mmHg}$ in the conservative group ( $\mathrm{p}<0.001$ ), in the third year $-53.1 \pm 41.4 \mathrm{mmHg}$ versus $-23.9 \pm 42.7 \mathrm{mmHg}(\mathrm{p}=\mathrm{NS})$, in the fifth year $-52.1 \pm 44.5$ $\mathrm{mmHg}$ versus $-3.0 \pm 63.2 \mathrm{mmHg}(\mathrm{p}<0.05)$. Change of NYHA class in the first year was $-1.1 \pm 0.4$ versus $-0.1 \pm 0.5$, in the third year $-1.0 \pm 0.6$ versus $0.1 \pm 0.4$, in the fifth year $-0.8 \pm 0.5$ versus $0.1 \pm 0.4$ (all $\mathrm{p}<0.001)$. Change of IVS thickness in the first year was $-3.8 \pm 2.9 \mathrm{~mm}$ versus $1.1 \pm 2.2 \mathrm{~mm}$, in the third year -5.5 $\pm 3.3 \mathrm{~mm}$ versus $2.5 \pm 4.3 \mathrm{~mm}$, in the fifth year $-5.9 \pm 3.4 \mathrm{~mm}$ versus $3.1 \pm 3.7 \mathrm{~mm}$ (all $\mathrm{p}<0.001)$. Comparison of all changes is described in Table 3. 
Tab. 2. Development of parameters in both groups (comparison of values between baseline and individual time period in both groups separately).

\begin{tabular}{|c|c|c|c|c|c|}
\hline & Periods & Cons. group & $\mathrm{p}$ & ASA group & $\mathrm{p}$ \\
\hline \multirow[t]{4}{*}{ NYHA class (mean) $\pm \mathrm{SD}$} & Baseline & $1.8 \pm 0.6$ & & $2.9 \pm 0.2$ & \\
\hline & 1st year & $1.8 \pm 0.6$ & NS & $1.8 \pm 0.5$ & $<0.001$ \\
\hline & 3rd year & $1.9 \pm 0.7$ & NS & $1.9 \pm 0.6$ & $<0.001$ \\
\hline & 5th year & $2.0 \pm 0.6$ & NS & $2.1 \pm 0.5$ & $<0.01$ \\
\hline \multirow[t]{4}{*}{ NYHA class $>$ II, n (\%) } & Baseline & $11(27)$ & & $39(100)$ & \\
\hline & 1st year & $7(20)$ & NS & $6(17)$ & $<0.001$ \\
\hline & 3rd year & $8(27)$ & NS & $8(30)$ & $<0.001$ \\
\hline & 5th year & $5(28)$ & NS & $9(45)$ & $<0.01$ \\
\hline \multirow[t]{4}{*}{ Resting LVOTG (mean) $\pm \mathrm{SD}, \mathrm{mmHg}$} & Baseline & $61.7 \pm 51.0$ & & $79.7 \pm 50.0$ & \\
\hline & 1st year & $55.2 \pm 51.5$ & NS & $25.5 \pm 18.8$ & $<0.001$ \\
\hline & 3rd year & $40.8 \pm 35.8$ & NS & $23.3 \pm 23.2$ & $<0.001$ \\
\hline & 5 th year & $51.0 \pm 67.5$ & NS & $26.5 \pm 29.3$ & $<0.001$ \\
\hline \multirow[t]{4}{*}{ Resting LVOTG - median, (IR), mmHg } & Baseline & $50(24-86)$ & & $83(45-100)$ & \\
\hline & 1st year & $40(17-75)$ & NS & $20(11-32)$ & $<0.001$ \\
\hline & 3rd year & $25(18-46)$ & NS & $19(11-26)$ & $<0.001$ \\
\hline & 5 th year & $25(16-37)$ & NS & $15(10-30)$ & $<0.001$ \\
\hline \multirow[t]{4}{*}{ Interventricular septum (mean) $\pm \mathrm{SD}, \mathrm{mm}$} & Baseline & $19.9 \pm 3.8$ & & $20.8 \pm 3.1$ & \\
\hline & 1st year & $20.8 \pm 4.3$ & NS & $16.4 \pm 3.3$ & $<0.001$ \\
\hline & 3rd year & $21.7 \pm 4.1$ & $<0.05$ & $15.4 \pm 3.0$ & $<0.001$ \\
\hline & 5th year & $21.8 \pm 4.7$ & $<0.01$ & $14.7 \pm 2.7$ & $<0.001$ \\
\hline \multirow{4}{*}{ Posterior wall (mean) $\pm \mathrm{SD}, \mathrm{mm}$} & Baseline & $14.5 \pm 2.3$ & & $15.6 \pm 3.5$ & \\
\hline & 1st year & $15.0 \pm 2.9$ & NS & $13.9 \pm 2.0$ & $<0.01$ \\
\hline & 3rd year & $15.4 \pm 2.8$ & NS & $13.6 \pm 2.1$ & $<0.01$ \\
\hline & 5 th year & $14.6 \pm 2.1$ & NS & $12.9 \pm 1.7$ & $<0.001$ \\
\hline \multirow[t]{4}{*}{$\mathrm{LV}$ end-diastolic diameter (mean) $\pm \mathrm{SD}, \mathrm{mm}$} & Baseline & $41.7 \pm 6.0$ & & $40.5 \pm 4.6$ & \\
\hline & 1st year & $41.7 \pm 4.6$ & NS & $44.5 \pm 4.7$ & $<0.05$ \\
\hline & 3rd year & $41.9 \pm 7.2$ & NS & $44.5 \pm 5.3$ & $<0.01$ \\
\hline & 5th year & $44.6 \pm 6.8$ & NS & $45.7 \pm 6.4$ & $<0.001$ \\
\hline \multirow[t]{4}{*}{$\overline{\mathrm{LV}}$ end-systolic diameter (mean) $\pm \mathrm{SD}, \mathrm{mm}$} & Baseline & $24.7 \pm 6.1$ & & $24.0 \pm 5.0$ & \\
\hline & 1st year & $26.3 \pm 6.4$ & NS & $28.3 \pm 5.2$ & $<0.01$ \\
\hline & 3rd year & $25.2 \pm 6.5$ & NS & $29.8 \pm 6.9$ & $<0.001$ \\
\hline & 5th year & $28.6 \pm 5.5$ & NS & $32.3 \pm 7.7$ & $<0.001$ \\
\hline \multirow[t]{4}{*}{ Left atrium (mean) $\pm \mathrm{SD}, \mathrm{mm}$} & Baseline & $42.8 \pm 5.6$ & & $44.6 \pm 7.3$ & \\
\hline & 1st year & $43.9 \pm 7.0$ & NS & $42.9 \pm 4.8$ & NS \\
\hline & 3rd year & $45.9 \pm 6.2$ & $<0.05$ & $43.1 \pm 6.2$ & NS \\
\hline & 5 th year & $47.4 \pm 6.1$ & $<0.01$ & $44.5 \pm 5.9$ & NS \\
\hline \multirow[t]{4}{*}{$\mathrm{LV}$ ejection fraction (mean) $\pm \mathrm{SD}, \%$} & Baseline & $68.1 \pm 7.2$ & & $65.7 \pm 6.5$ & \\
\hline & 1st year & $66.1 \pm 6.9$ & NS & $61.3 \pm 7.0$ & $<0.05$ \\
\hline & 3rd year & $67.0 \pm 6.7$ & NS & $62.9 \pm 8.8$ & NS \\
\hline & 5 th year & $65.6 \pm 8.7$ & NS & $59.6 \pm 10.6$ & $<0.01$ \\
\hline \multirow[t]{4}{*}{ Right ventricle (mean) $\pm \mathrm{SD}, \mathrm{mm}$} & Baseline & $28.2 \pm 3.6$ & & $28.2 \pm 3.9$ & \\
\hline & 1st year & $28.8 \pm 4.8$ & NS & $28.7 \pm 4.1$ & NS \\
\hline & 3 rd year & $29.2 \pm 3.7$ & NS & $30.3 \pm 5.3$ & NS \\
\hline & 5 th year & $30.4 \pm 2.9$ & NS & $29.8 \pm 5.1$ & NS \\
\hline \multirow[t]{4}{*}{ Mitral regurgitation (mean) $\pm \mathrm{SD}$} & Baseline & $0.8 \pm 0.7$ & & $1.4 \pm 0.7$ & \\
\hline & 1st year & $0.8 \pm 0.7$ & NS & $1.1 \pm 0.6$ & NS \\
\hline & 3rd year & $0.9 \pm 0.7$ & NS & $1.1 \pm 0.6$ & NS \\
\hline & 5 th year & $0.9 \pm 0.7$ & NS & $1.0 \pm 0.4$ & $<0.05$ \\
\hline \multirow[t]{4}{*}{ Systolic anterior motion, $\mathrm{n}(\%)$} & Baseline & $37(90)$ & & $37(95)$ & \\
\hline & 1st year & $28(80)$ & NS & $25(69)$ & NS \\
\hline & 3rd year & $23(79)$ & NS & $18(67)$ & $<0.05$ \\
\hline & 5 th year & $15(83)$ & NS & $17(85)$ & NS \\
\hline
\end{tabular}

Cons. - Conservative, ASA - alcohol septal ablation, SD - standard deviation, NS - non-significant, LVOTG - left ventricular outflow tract gradient, LV - left ventricle, IR - interquartile range

\section{Discussion}

In HCM patients with persistent obstruction in LVOT, a gradual increase in LV wall thickness may be observed over the years (1). Gradient in LVOT is highly variable, besides hypertrophy of IVS and mitral valve pathology including its accessory appara- tus, obstruction in LVOT depends also on a degree of hydration, stress conditions or chamber contractility, therefore LVOTG may vary according to activities and position of the patient, intake of fluid and food. Systolic function usually remains preserved for a long time, but in a small proportion of cases (about 5-10\%) it can transform into so-called ,end-stage“ or „burned-out“ phase, 
Tab. 3. Changes of parameters (comparison of parameter change between both groups).

\begin{tabular}{|c|c|c|c|c|}
\hline & Periods & Cons. group & ASA group & $\mathrm{p}$ \\
\hline NYHA class (mean) $\pm \mathrm{SD}$ & $\begin{array}{l}0-1 \text { year } \\
0-3 \text { year } \\
0-5 \text { year }\end{array}$ & $\begin{array}{c}-0.1 \pm 0.5 \\
0.1 \pm 0.4 \\
0.1 \pm 0.4\end{array}$ & $\begin{array}{l}-1.1 \pm 0.4 \\
-1.0 \pm 0.6 \\
-0.8 \pm 0.5\end{array}$ & $\begin{array}{l}<0.001 \\
<0.001 \\
<0.001\end{array}$ \\
\hline Resting LVOTG (mean) $\pm \mathrm{SD}, \mathrm{mmHg}$ & $\begin{array}{l}0-1 \text { year } \\
0-3 \text { year } \\
0-5 \text { year }\end{array}$ & $\begin{array}{c}-5.5 \pm 47.1 \\
-23.9 \pm 42.7 \\
-3.0 \pm 63.2\end{array}$ & $\begin{array}{l}-53.7 \pm 36.4 \\
-53.1 \pm 41.4 \\
-52.1 \pm 44.5 \\
\end{array}$ & $\begin{array}{c}<0.001 \\
\mathrm{NS} \\
<0.05\end{array}$ \\
\hline Interventricular septum (mean) $\pm \mathrm{SD}, \mathrm{mm}$ & $\begin{array}{l}0-1 \text { year } \\
0-3 \text { year } \\
0-5 \text { year }\end{array}$ & $\begin{array}{l}1.1 \pm 2.2 \\
2.5 \pm 4.3 \\
3.1 \pm 3.7 \\
\end{array}$ & $\begin{array}{l}-3.8 \pm 2.9 \\
-5.5 \pm 3.3 \\
-5.9 \pm 3.4\end{array}$ & $\begin{array}{l}<0.001 \\
<0.001 \\
<0.001\end{array}$ \\
\hline Posterior wall (mean) $\pm \mathrm{SD}, \mathrm{mm}$ & $\begin{array}{l}0-1 \text { year } \\
0-3 \text { year } \\
0-5 \text { year }\end{array}$ & $\begin{array}{l}0.4 \pm 1.8 \\
0.8 \pm 2.3 \\
0.2 \pm 2.5 \\
\end{array}$ & $\begin{array}{l}-2.2 \pm 2.8 \\
-2.6 \pm 3.7 \\
-3.1 \pm 4.0\end{array}$ & $\begin{array}{l}<0.01 \\
<0.01 \\
<0.01 \\
\end{array}$ \\
\hline $\mathrm{LV}$ end-diastolic diameter (mean) $\pm \mathrm{SD}, \mathrm{mm}$ & $\begin{array}{l}0-1 \text { year } \\
0-3 \text { year } \\
0-5 \text { year }\end{array}$ & $\begin{array}{c}-1.1 \pm 3.7 \\
-0.7 \pm 5.9 \\
1.2 \pm 4.1\end{array}$ & $\begin{array}{l}3.7 \pm 5.3 \\
4.1 \pm 6.6 \\
5.4 \pm 5.7\end{array}$ & $\begin{array}{l}<0.01 \\
<0.05 \\
<0.05\end{array}$ \\
\hline $\mathrm{LV}$ end-systolic diameter (mean) $\pm \mathrm{SD}, \mathrm{mm}$ & $\begin{array}{l}0-1 \text { year } \\
0-3 \text { year } \\
0-5 \text { year }\end{array}$ & $\begin{array}{c}-0.1 \pm 5.3 \\
0.7 \pm 6.7 \\
2.7 \pm 6.1 \\
\end{array}$ & $\begin{array}{l}4.9 \pm 6.0 \\
6.3 \pm 8.1 \\
8.8 \pm 8.5 \\
\end{array}$ & $\begin{array}{l}<0.05 \\
<0.05 \\
<0.05 \\
\end{array}$ \\
\hline Left atrium (mean) $\pm \mathrm{SD}, \mathrm{mm}$ & $\begin{array}{l}0-1 \text { year } \\
0-3 \text { year } \\
0-5 \text { year }\end{array}$ & $\begin{array}{l}0.5 \pm 4.5 \\
3.1 \pm 4.0 \\
4.8 \pm 5.5 \\
\end{array}$ & $\begin{array}{l}-3.2 \pm 5.9 \\
-1.9 \pm 6.1 \\
-1.2 \pm 7.1 \\
\end{array}$ & $\begin{array}{c}\text { NS } \\
<0.01 \\
<0.05 \\
\end{array}$ \\
\hline $\mathrm{LV}$ ejection fraction (mean) $\pm \mathrm{SD}, \%$ & $\begin{array}{l}0-1 \text { year } \\
0-3 \text { year } \\
0-5 \text { year }\end{array}$ & $\begin{array}{c}-1.0 \pm 10.1 \\
-2.7 \pm 7.9 \\
-2.3 \pm 10.2 \\
\end{array}$ & $\begin{array}{c}-6.7 \pm 5.5 \\
-4.0 \pm 11.0 \\
-7.0 \pm 12.0 \\
\end{array}$ & $\begin{array}{l}\text { NS } \\
\text { NS } \\
\text { NS } \\
\end{array}$ \\
\hline Right ventricle (mean) $\pm \mathrm{SD}, \mathrm{mm}$ & $\begin{array}{l}0-1 \text { year } \\
0-3 \text { year } \\
0-5 \text { year }\end{array}$ & $\begin{array}{c}0.8 \pm 3.8 \\
-0.5 \pm 4.0 \\
1.8 \pm 3.5 \\
\end{array}$ & $\begin{array}{l}0.4 \pm 4.6 \\
1.6 \pm 4.5 \\
2.0 \pm 4.6 \\
\end{array}$ & $\begin{array}{l}\text { NS } \\
\text { NS } \\
\text { NS } \\
\end{array}$ \\
\hline$\overline{\text { Mitral regurgitation (mean) } \pm \mathrm{SD}}$ & $\begin{array}{l}0-1 \text { year } \\
0-3 \text { year } \\
0-5 \text { year }\end{array}$ & $\begin{array}{c}-0.1 \pm 0.8 \\
0.0 \pm 0.7 \\
0.0 \pm 0.6\end{array}$ & $\begin{array}{l}-0.3 \pm 0.8 \\
-0.5 \pm 0.9 \\
-0.7 \pm 0.7\end{array}$ & $\begin{array}{c}\mathrm{NS} \\
\mathrm{NS} \\
<0.05\end{array}$ \\
\hline$\overline{\text { SAM, n; (+)appearance/(-)disappearance }}$ & $\begin{array}{l}0-1 \text { year } \\
0-3 \text { year } \\
0-5 \text { year }\end{array}$ & $\begin{array}{l}(+) 3 /(-) 0 \\
(+) 3 /(-) 3 \\
(+) 3 /(-) 2\end{array}$ & $\begin{array}{l}+) 0 /(-) 4 \\
(+) 0 /(-) 7 \\
(+) 0 /(-) 3\end{array}$ & $\begin{array}{c}<0.01 \\
\text { NS } \\
\text { NS } \\
\end{array}$ \\
\hline
\end{tabular}

Cons. - Conservative, ASA - alcohol septal ablation, SD - standard deviation, NS - non-significant, LVOTG - left ventricular outflow tract gradient, LV - left ventricle, SAM - systolic anterior motion

which is characterized by decrease of LVEF and very poor prognosis (3). In contrast, diastolic function showed faster progression over the years, because HCM is characterized, besides hypertrophy itself, by typical increase of interstitial fibrosis and the consequent deterioration of LV wall compliance. HCM in some cases may develop into restrictive phenotype with thinning of LV walls and significant dilatation of both atria. All the above mentioned mechanisms lead to symptoms deterioration and are also associated with poor prognosis. In literature, there are many works dealing with issues of alcohol septal ablation and documenting its safety and efficacy $(20,21,22)$. However, much less studies concern with comparing of invasive and conservative approach. According to our best knowledge, only two works that compared invasive and conservative treatment were published in the last years. In first of them, Ball et al confirmed that patients with invasive therapy (ASA, surgical myectomy or dual-chamber pacing) had lower overall mortality than the group treated pharmacologically corresponding to the degree of LVOTG reduction (11). Second, Yang et al showed similar results as Ball on survival in the ASA patients (23). Both these studies compared prognostic indicators of these two treatment strategies and demonstrated a superiority of invasive access, respectively ASA, in patients with HOCM. Whereas in our study, we did not deal with prognostic indicators, but we focused on the comparison of echocardiographic parameters and functional status in different therapeutic approaches (invasive versus conservative). We tried to reveal a potential positive effect of LVOTG decrease on LV remodeling.

In the conservatively treated group, "natural" morphological development of this disease was documented during the follow-up with an increase of IVS thickness and gradual LA dilatation, which was selected as a marker reflecting diastolic function. Both above mentioned parameters showed a statistically significant increase after three years, yet with ongoing trend for the rest of the trial. Whereas in the ASA group after the first year, a significant thinning of IVS was observed and LA size was slightly diminished. IVS thinning continued also in the subsequent years (Fig. 2a, b). However, when we compared changes of LA size between these two groups, we established a statistically significant difference in the third and the fifth year. This could be a sign of a possible effect of LVOTG decrease caused by ASA on the favorable development of diastolic function in long-term follow-up. In literature, many trials documenting a beneficial effect of ASA on the diastolic function 
were published (24, 25, and 26). Enlarged LA, as was seen in both groups, is a common finding in HCM patients. The cause of this enlargement is the diastolic dysfunction associated with chronically elevated filling pressures of LV. Another option is, especially in obstructive types, the presence of mitral regurgitation due to the SAM. LA size also correlates with the severity of symptoms, the presence of atrial fibrillation, severity of LVOTG and especially with mortality, which was confirmed by Nistri et al (27). In the context of LV remodeling after the ASA, simultaneously with LVOTG decrease and IVS thinning, a statistically significant thinning of PW occurred in all reporting periods. This confirms the hypothesis that there is a total regression of LV hypertrophy even outside the intervened LV segments due to an afterload decrease. LVOTG in the conservatively treated group slightly declined during the observation, but without a statistical significance. Similarly, NYHA classification remained almost stationary, despite the optimization of pharmacotherapy performed during the visits (however in this group, symptoms were less urgent than in the ASA group, because the higher NYHA class in the ASA group is based on general indicative principles of this treatment). Conversely, in the group treated with ASA, a decrease of LVOTG after the first year was recorded and correlated with improvement of NYHA classification with a drop of at least 1 class. Favorable values of LVOTG and NYHA class remained stationary for the rest of the study. LVOTG value remained in mid-term and long-term duration under the limit of 30 $\mathrm{mmHg}$. Comparing the changes of these two parameters between both groups, a greater improvement was clearly observed in the ASA group, even though at three years of follow-up there was not statistically significant difference in the change of LVOTG. Patients were further divided into the two groups according to the severity of symptoms, mildly symptomatic (NYHA $\leq$ II) and more symptomatic (NYHA $<$ II). In the interventionally treated group, all subjects at baseline were highly symptomatic and during the first year $83 \%$ of them clinically improved to mildly symptomatic group. Conservatively treated group showed no significant change of this parameter during the follow-up. Similar improvement of the parameters as in our group was observed in a large multicenter trial of Scandinavian authors in short-term and long-term period with a decrease of resting LVOTG in the first year from 58 to 12 $\mathrm{mmHg}(\mathrm{p}<0.001)$, stationary for the whole period and improvement of the NYHA class (reduced proportion of patients NYHA III/IV from $94 \%$ at baseline to $24 \%$ in the first year, $\mathrm{p}<0.001$ ) (28). Another study from Polish authors reported LVOTG decline from $89 \pm 44 \mathrm{mmHg}$ to $17 \pm 17 \mathrm{mmHg}$ and IVS thinning from $24 \pm 4 \mathrm{~mm}$ to $18 \pm 5 \mathrm{~mm}$ (both $\mathrm{p}<0.01$ ) in short-term monitoring (29). A number of other authors reported similar results (30, $31,32,33,34)$. Proportional decrease of the SAM incidence was certainly related to the LVOTG decline and LV remodeling in the interventional arm, which reached in the first and the third year of follow-up statistical significance, associated likewise with a reduction of incidence and degree of mitral regurgitation. As a part of LV remodeling after LVOTG decline, we observed thinning of LV walls, as well as enlargement of LV cavity represented by LVEDD and LVESD parameters, demonstrated in the ASA group after the first year already, with the trend ongoing in the next years. The trend toward to an increase of the size of LVEDD and LVESD was also observed in the conservatively treated group, but not statistically significant. From comparison of the changes in these two parameters between both groups, the increase of LV dimensions is apparent in the interventionally treated group. Veselka et al presented in 5-year follow-up after ASA an improvement of the NYHA class from $2.9 \pm 0.5$ to $1.6 \pm 0.8$, LVOTG decline from 68 $\pm 42 \mathrm{mmHg}$ to $20 \pm 25 \mathrm{mmHg}$, LVEDD enlargement from $43 \pm$ $5 \mathrm{~mm}$ to $47 \pm 5 \mathrm{~mm}$, IVS thinning from $21 \pm 4 \mathrm{~mm}$ to $14 \pm 4 \mathrm{~mm}$ ( $p<0.01$ for all) corresponding with our results (35). LV systolic function in both groups underwent a slight decline from baseline, in the ASA group even statistically significant in the first and the fifth year of follow-up, however from the clinical point of view, we did not consider this change important. Comparing differences in LVEF decline, no significant change between both groups was detected in any reference period, which just documents the safety of this intervention method. The average value of LVEF remained preserved in both groups at the end of the study (32). The above mentioned LVEF decrease in the ASA group was caused in part by immediate complication of procedure in one patient, who experienced leak of alcohol into the periphery of LCA, which caused myocardial infarction in the apex of LV. The second patient in the same group had documented LVEF decline after 3 years to $40 \%$ and after 5 years even to $25 \%$. This was related probably to the "end-stage" phase of this disease, without connection with the actual procedure. The RV dimension and change of its size during the follow-up was not statistically or clinically significant.

In our study, we did not deal with the influence of alcohol doses on the possible development of the above mentioned parameters, but Veselka et al demonstrated almost identical effect of low dose of alcohol (1-2 ml) compared to higher dose of alcohol (>2 ml) to LVOTG decline in long-term observation (36). The average dose of ethanol in our group was $2.2 \pm 0.7 \mathrm{ml}$ used for ablation of one septal branch, which is almost in-line with recent studies, where the average dose of alcohol was about $2 \mathrm{ml}$ (37). A trend to reduce the dose of alcohol to the amount of $2 \mathrm{ml}$ was observed globally because of lower mortality and reduced risk of atrioventricular blockade with need for permanent pacemaker implantation (38, 39). The higher average of alcohol consumption in our study was due to the higher doses used in patients intervened at the beginning period of using this method.

Another therapeutic modality, surgical myectomy, which is listed as the method of choice in the treatment of obstruction mainly by American authors, has according to literature comparable effect on LV remodeling, LVOTG reduction and decline of NYHA class as ASA $(40,41,42)$. DDD pacemaker implantation with apical pre-excitation also has a beneficial effect on LV remodeling and improvement of patients' symptoms. The effect of stimulation on LVOTG reduction is smaller and the achievement of comparable decline requires a longer time period, which was the cause of suboptimal LVOTG decrease in the studies PIC and M-PATHY with a shorter follow-up $(13,14)$. A multicentric study comparing ASA and DDD pacing showed a statistically significant LVOTG decrease and NYHA class improvement in both groups, although the effect of ASA was more pronounced and the result 
was achieved earlier (12). Comparing the effect of various invasive treatments, the improvement of the prognosis was achieved only in the groups treated with ASA and surgical myectomy, while DDD pacing worsen prognosis (11).

\section{Limitations}

The most important limitation of our study was the fact that it was a retrospective, non-randomized study with a relatively small number of patients, particularly when comparing the results in long-term period. Likewise, a number of other parameters were not available in all patients because of the fact that some of them had become a standard only in recent years (e. g. Tissue Doppler Imaging parameters, more detailed diastolic function evaluation, etc.). Furthermore, patients with implanted dual-chamber PM/ ICD because of atrioventricular blockade with permanent apical stimulation were not included. Another major limitation of this study was the indirect assessment of diastolic function by the LA size, which we chose as its correlate, with the knowledge of some inaccuracy of such approach, because in the patients from the initial period of this study parameters needed for diastolic function assessment were not available.

\section{Conclusion}

Our results showed for the first time that decline of LVOTG after ASA made the difference in development of other echocardiographic parameters between the conservatively treated group and the group treated by ASA. This suggests that the marked LVOTG decrease after ASA results in an improvement or stabilization of LV morphology. On contrary, in the conservative treated group, we saw an unfavorable development of these parameters. Likewise, improvement of functional status was significantly more expressed in the group treated with ASA. Prevention of unfavorable course of the disease by LVOTG reduction raised the question, whether it would not be appropriate to indicate the intervention leading to LVOTG reduction even in less symptomatic individuals to prevent the latter unfavorable course of this disease.

\section{References}

1. Gersh BJ, Maron BJ, Bonow RO et al. $2011 \mathrm{ACCF} / \mathrm{AHA}$ guideline for the diagnosis and treatment of hypertrophic cardiomyopathy: a report of the American College of Cardiology Foundation/American Heart Association Task Force on Practice Guidelines. J Am Coll Cardiol 2011; 58 (25): 2703-2738.

2. Veselka J. Historical milestones and progress in the research on alcohol septal ablation for hypertrophic obstructive cardiomyopathy. Can J Cardiol 2014; 30 (1): 46-51.

3. Elliott PM, Anastasakis A, Borger MA et al. 2014 ESC Guidelines on diagnosis and management of hypertrophic cardiomyopathy: the Task Force for the Diagnosis and Management of Hypertrophic Cardiomyopathy of the European Society of Cardiology (ESC). Eur Heart J 2014; 35 (39): 2733-2779.

4. Enriquez AD, Goldman ME. Management of hypertrophic cardiomyopathy. Ann Glob Health 2014; 80 (1): 35-45.
5. Veselka J. Twenty years of alcohol septal ablation document more than a history of a single interventional procedure. Cor et Vasa 2015; 57 : e16-e27.

6. Veselka J. How to treat obstructions in patients with hypertrophic cardiomyopathy. Int J Angiol 2015; 24 (2): 121-126.

7. Maron BJ, Ommen SR, Semsarian C, Spirito P, Olivotto I, Maron MS. Hypertrophic cardiomyopathy: present and future, with translation into contemporary cardiovascular medicine. J Am Coll Cardiol 2014; 64 (1): 83-99.

8. Seggewiss H. Medical therapy versus interventional therapy in hypertrophic obstructive cardiomyopathy. Curr Control Trials Cardiovasc Med 2000; 1 (2): 115-119.

9. Harrison DC, Braunwald E, Glick G, Mason DT, Chidsey CA, Ross J Jr. Effects of beta adrenergic blockade on the circulation, with particular reference to observations in patients with hypertrophic subaortic stenosis. Circulation 1964; 29: 84-98.

10. Epstein SE, Rosing DR. Verapamil: its potential for causing serious complications in patients with hypertrophic cardiomyopathy. Circulation 1981; 64: 437-441.

11. Ball W, Ivanov J, Rakowski H et al. Long-term survival in patients with resting obstructive hypertrophic cardiomyopathy comparison of conservative versus invasive treatment. J Am Coll Cardiol 2011; 58 (22): 2313-2321.

12. Krejci J, Gregor P, Zemanek D et al. Comparison of long-term effect of dual-chamber pacing and alcohol septal ablation in patients with hypertrophic obstructive cardiomyopathy. Sci World J 2013; 2013: 629650.

13. Kappenberger $\mathbf{L}$, Linde $\mathbf{C}$, Daubert $\mathbf{C}$ et al. Pacing in hypertrophic obstructive cardiomyopathy. A randomized crossover study. PIC Study Group. Eur Heart J 1997; 18 (8): 1249-1256.

14. Maron BJ, Nishimura RA, McKenna WJ, Rakowski H, Josephson ME, Kieval RS. Assessment of permanent dual-chamber pacing as a treatment for drug- refractory symptomatic patients with obstructive hypertrophic cardiomyopathy: a randomized, double-blind, crossover study (M-PATHY). Circulation 1999; 99 (22): 2927-2933.

15. Sigwart U. Non-surgical myocardial reduction for hypertrophic obstructive myocardial infarction. Lancet 1995; 346: 211-214.

16. Alcala-Fdez J, Sanchez L, Garcia MJ et al. KEEL: A Software Tool to Assess Evolutionary Algorithms for Data Mining Problems. Soft Computing 2009; 13 (3): 307-318.

17. Popescu BA, Rosca M, Schwammenthal E. Dynamic obstruction in hypertrophic cardiomyopathy. Curr Opin Cardiol 2015; 30 (5): 468-474.

18. Schuller JL, Zipse MM, Krantz MJ et al. Incidence and predictors of late complete heart block after alcohol septal ablation treatment of hypertrophic obstructive cardiomyopathy. J Interv Cardiol 2015; 28 (1): 90-97.

19. Zemanek D, Tomasov P, Bělehrad M et al. Comparison of sublingual isosorbide dinitrate and Valsalva maneuver for detection of obstruction in hypertrophic cardiomyopathy. Arch Med Sci 2015; 11 (4): 751-755.

20. Veselka J, Jensen MK, Liebregts $M$ et al. Long-term clinical outcome after alcohol septal ablation for obstructive hypertrophic cardiomyopathy: results from the Euro-ASA registry. Eur Heart J 2016; 37 (19): 1517-1523.

21. Liebregts M, Steggerda RC, Vriesendorp PA et al. Long-Term Outcome of Alcohol Septal Ablation for Obstructive Hypertrophic Cardiomyopathy in the Young and the Elderly. JACC Cardiovasc Interv 2016; 9 (5): 463-469. 
562-570

22. Lu M, Du H, Gao Z et al. Predictors of Outcome After Alcohol Septal Ablation for Hypertrophic Obstructive Cardiomyopathy: An Echocardiography and Cardiovascular Magnetic Resonance Imaging Study. Circ Cardiovasc Interv 2016; 9 (3): e002675.

23. Yang YJ, Fan CM, Yuan JQ et al. Survival after alcohol septal ablation versus conservative therapy in obstructive hypertrophic cardiomyopathy. Cardiol J 2015; 22 (6): 657-664.

24. Jassal DS, Neilan TG, Fifer MA et al. Sustained improvement in left ventricular diastolic function after alcohol septal ablation for hypertrophic obstructive cardiomyopathy. Eur Heart J 2006; 27 (15): 1805-1810.

25. Sorajja P, Nishimura RA, Ommen SR, Rihal CS, Gersh BJ, Holmes DR Jr. Effect of septal ablation on myocardial relaxation and left atrial pressure in hypertrophic cardiomyopathy an invasive hemodynamic study. JACC Cardiovasc Interv 2008; 1 (5): 552-560.

26. Chen YZ, Duan FJ, Yuan JS et al. Effects of alcohol septal ablation on left ventricular diastolic filling patterns in obstructive hypertrophic cardiomyopathy. Heart Vessels 2016; 31 (5): 744-751.

27. Nistri S, Olivotto I, Betocchi S et al. Prognostic significance of left atrial size in patients with hypertrophic cardiomyopathy (from the Italian Registry for Hypertrophic Cardiomyopathy). Am J Cardiol 2006; 98 (7): 960-965.

28. Jensen MK, Almaas VM, Jacobsson L et al. Long-term outcome of percutaneous transluminal septal myocardial ablation in hypertrophic obstructive cardiomyopathy: a Scandinavian multicenter study. Circ Cardiovasc Interv 2011; 4 (3): 256-265

29. Tekieli $\mathbf{L}$, Pieniazek P, Podolec $P$ et al. Percutaneous transluminal septal myocardial ablation: early results and long-term follow-up. Przegl Lek 2006; 63 (8): 628-632.

30. Seggewiss H, Gleichmann U, Faber L, Fassbender D, Schmidt HK, Strick S. Percutaneous transluminal septal myocardial ablation in hypertrophic obstructive cardiomyopathy: acute results and 3-month follow-up in 25 patients. J Am Coll Cardiol 1998; 31 (2): 252-258.

31. Malek LA, Chojnowska L, Klopotowski M et al. Long term exercise capacity in patients with hypertrophic cardiomyopathy treated with percutaneous transluminal septal myocardial ablation. Eur J Heart Fail 2008; 10 (11): 1123-1126.

32. Moss TJ, Krantz MJ, Zipse MM et al. Left ventricular systolic function following alcohol septal ablation for symptomatic hypertrophic cardiomyopathy. Am J Cardiol 2014; 113 (8): 1401-1404.
33. Veselka J, Lawrenz T, Stellbrink C et al. Early outcomes of alcohol septal ablation for hypertrophic obstructive cardiomyopathy: a European multicenter and multinational study. Catheter Cardiovasc Interv 2014; 84 (1): 101-107.

34. Leal S, Galeote G, Jiménez-Valero $S$ et al. Percutaneous alcohol septal ablation for hypertrophic obstructive cardiomyopathy: technical review and long-term clinical and echocardiographic outcomes. Rev Port Cardiol 2012; 31 (5): 363-371.

35. Veselka J, Krejěí J, Tomašov P, Zemánek D. Long-term survival after alcohol septal ablation for hypertrophic obstructive cardiomyopathy: a comparison with general population. Eur Heart J 2014; 35 (30): 2040-2045.

36. Veselka J, Tomašov P, Zemánek D. Long-term effects of varying alcohol dosing in percutaneous septal ablation for obstructive hypertrophic cardiomyopathy: a randomized study with a follow-up up to 11 years. Can J Cardiol 2011; 27 (6): 763-767.

37. Sathyamurthy I, Nayak R, Oomman A et al. Alcohol septal ablation for hypertrophic obstructive cardiomyopathy -8 years follow up. Indian Heart J 2014; 66 (1): 57-63.

38. Aqel R, Hage FG, AlJaroudi $W$ et al. How much alcohol should we infuse in the coronary artery of hypertrophic cardiomyopathy patients? J Invasive Cardiol 2010; 22 (1): 22-26.

39. Kuhn H, Lawrenz T, Lieder $F$ et al. Survival after transcoronary ablation of septal hypertrophy in hypertrophic obstructive cardiomyopathy (TASH): a 10 year experience. Clin Res Cardiol 2008; 97 (4): 234-243.

40. Steggerda RC, Damman K, Balt JC, Liebregts M, ten Berg JM, van den Berg MP. Periprocedural complications and long-term outcome after alcohol septal ablation versus surgical myectomy in hypertrophic obstructive cardiomyopathy: a single-center experience. JACC Cardiovasc Interv 2014; 7 (11): 1227-1234.

41. Leonardi RA, Kransdorf EP, Simel DL, Wang A. Meta-analyses of septal reduction therapies for obstructive hypertrophic cardiomyopathy: comparative rates of overall mortality and sudden cardiac death after treatment. Circ Cardiovasc Interv 2010; 3 (2): 97-104.

42. Liebregts M, Vriesendorp PA, Mahmoodi BK et al. A Systematic Review and Meta-Analysis of Long-Term Outcomes After Septal Reduction Therapy in Patients With Hypertrophic Cardiomyopathy. JACC Heart Fail 2015; 3 (11): 896-905.

Received June 6, 2016. Accepted July 3, 2016. 